\title{
Protective Role of Nitric Oxide Against Cardiac Arrhythmia - An Update
}

\author{
Dylan E. Burger ${ }^{1}$ and Qingping Feng, ${ }^{*}$
}

\author{
${ }^{1}$ Kidney Research Centre, Ottawa Hospital Research Institute, University of Ottawa, Ottawa; ${ }^{2}$ Department of \\ Physiology and Pharmacology, University of Western Ontario, London, Ontario, Canada
}

\begin{abstract}
Nitric oxide (NO), a ubiquitous cell signalling molecule, plays an important role in the regulation of cardiovascular function. NO is produced by all cell types in the heart and is widely implicated in vasodilation, inflammation, ischemic preconditioning and cell death. Mounting evidence now suggests that NO also provides protection against cardiac arrhythmia. Pharmacological studies using NO precursors and NO donors have observed an anti-arrhythmic effect, while inhibitors of NO biosynthesis increase arrhythmia, or attenuate anti-arrhythmic actions in a variety of animal models. Additionally, genetic studies from animals deficient in nitric oxide synthase (NOS) enzymes have found increased susceptibility to pharmacological or ischemia-induced arrhythmia while transgenic mice overexpressing certain NOS isozymes may be protected. In the human population polymorphisms in NOS enzymes, or differences in the levels of endogenous inhibitors of NO synthesis may also be important determinants of arrhythmic susceptibility. The precise mechanisms of NO-mediated protection from arrhythmia are still under investigation but may include reductions in calcium overload, regulation of gap junction/connexin expression, reductions in oxidative stress, and regulation of sympathetic activity. This review examines the pharmacological, genetic, and clinical evidence of a role for NO in reducing cardiac arrhythmia and discusses possible mechanisms of NO-mediated protection against arrhythmia.
\end{abstract}

Keywords: Nitric oxide, nNOS, arrhythmia, calcium, electrophysiology.

\section{INTRODUCTION}

For almost 30 years nitric oxide (NO) has been known to be a critical determinant of vascular tone [1-5]. Since the early reports, which identified NO as the endotheliumderived relaxation factor, our knowledge has expanded considerably and it is now well-established that NO plays an important role in mammalian biology and regulates the functions of many organs including the brain, kidney, blood, muscle, skeletal, reproductive, gastrointestinal, immune and cardiovascular systems [6-8].

In mammals, NO is produced primarily through the conversion of L-arginine to L-citrulline by one of three nitric oxide synthase isozymes termed neuronal, inducible, or endothelial (nNOS, iNOS, and eNOS, respectively). Conversion of inorganic nitrate and nitrite to NO through nitrogen cycling pathways may be an additional source of NO in certain systems $[9,10]$. All components of the cardiovascular system produce NO, with the heart expressing each NOS isoform and containing the necessary reduction pathways for NOS-independent NO production [7, 11, 12].

The development of pharmacological inhibitors of NOS, as well as genetic models of NOS deficiency have led to a much deeper understanding of NO biology and it is now clear that NO is a key component of the cardiovascular system. The cardiovascular effects of NO, which are both isoform- and concentration-dependent, extend well beyond

*Address correspondence to this author at the Department of Physiology and Pharmacology, University of Western Ontario, London, Ontario, Canada N6A 5C1; Tel: 519-850-2989; E-mail: qfeng@uwo.ca vasodilation and include regulation of cardiomyocyte death, modulation of the inflammatory response, baroreceptor function, pathogenesis of atherosclerosis, and ischemic injury. These effects have been covered extensively in several excellent papers $[7,8,12-16]$ and are beyond the scope of this review. In this review we examine the mounting evidence on the protective role of $\mathrm{NO}$ in preventing cardiac arrhythmia. Pharmacological, genetic, and clinical evidence will be outlined and possible mechanisms of action will be explored.

\section{PHARMACOLOGICAL EVIDENCE}

The earliest evidence that NO provides protection against cardiac arrhythmia came from studies using nitrovasodilators. Nitroglycerin has long been known to be of utility for protection against ventricular arrhythmias [1720]. However, these effects were traditionally attributed to the drug's capacity to reduce ischemic damage to the heart rather than direct actions by NO on cardiac electrophysiology [20]. Similarly, Mukherjee and colleagues reported in 1976 that sodium nitroprusside reduced ventricular arrhythmia in hypertensive patients with acute myocardial infarction but could not rule out a role for blood pressure reduction in the observed effects [21]. While the anti-arrhythmic effects of these agents were not immediately attributed to direct NO-mediated effects, subsequent studies have confirmed nitroglycerin's anti-arrhythmic action independent of ischemic protection [22], and sodium nitroprusside has been shown to prevent $\mathrm{Ca}^{2+}$ overload and arrhythmogenesis in isolated cardiomyocytes [23]. Thus the anti-arrhythmic effects of nitrovasodilators appear to be at least partially independent of any ischemic protection or 
blood pressure reduction and likely also involve direct NOmediated actions.

Beginning in the early-mid 1990s, advances in our knowledge of NO biology, and the development of pharmacological inhibitors targeting NOS isozymes, led to further support for a protective, anti-arrhythmic action of NO. Wainwright and Martorana provided evidence that NO suppresses arrhythmia using a porcine model of ischemiareperfusion $(\mathrm{I} / \mathrm{R})$ injury where they found that the $\mathrm{NO}$ donor pirsidomine reduced ventricular arrhythmias as well as the time to onset of ventricular fibrillation [24]. As in the nitrovasodilator studies, these reductions in arrhythmia were attributed to the hemodynamic effects of NO and reductions in ischemic injury. Vegh and colleagues examined the role of $\mathrm{NO}$ in mediating the effects of ischemic preconditioning in dogs. Ischemic preconditioning significantly reduced the incidence of ventricular tachycardia and fibrillation following subsequent ischemic injury [25]. Treatment with the NOS inhibitor, L-nitro arginine methyl ester (L-NAME) immediately prior to preconditioning blocked preconditioning-mediated protection, suggesting a role for NOS-derived NO production in preconditioning [25]. Using a similar approach, the authors went on to identify a role for NO in the anti-arrhythmic effects of bradykinin during ischemia [26]. One study, utilizing multiple NO modulators including L-NAME, L-arginine (the NOS substrate) and sodium nitroprusside (an NO donor), reported that inhibition of NO resulted in an increase in ventricular fibrillation in isolated rat hearts subjected to I/R [27]. The effects of LNAME were attenuated by co-treatment with either Larginine or sodium nitroprusside further confirming the role of NO in this endogenous protection against arrhythmia. A follow-up study, using a selective inhibitor of nNOS (7-nitro indazole) suggested that nNOS may be responsible for the endogenous NO release in rats, but this effect may be due to other NOS isozymes in rabbits [28]. Thus, the enzymatic source of NO which mediates protection against arrhythmia may be species dependent.

Experiments examining the anti-arrhythmic effects of estrogen have also provided insight into the role of NO in arrhythmia. Estrogen reduces arrhythmogenesis in isolated cardiomyocytes, protects against I/R-induced arrhythmia in dogs, and decreases isoproteronol-induced arrhythmia in rats [29-32]. Additionally, female rats are particularly resistant to myocardial ischemia-induced arrhythmia compared to their male counterpart [33]. NO has been implicated as a potential downstream mediator of the anti-arrhythmic effects of estrogen. In rabbit [34] and canine [35] models of I/R, the anti-arrhythmic effects of estrogen are attenuated by treatment with the NOS inhibitor L-NAME. Furthermore, NO has been implicated in estrogen-mediated preservation of connexin 43 and reductions in arrhythmia following myocardial infarction in rats [36]. Thus, NO may be an important downstream mediator of estrogen-mediated protection from arrhythmia.

While the majority of pharmacological studies point to an anti-arrhythmic effect of NO, a few studies have failed to observe an effect on arrhythmia. Barnes and Coker examined the effects of NO donors on I/R-induced arrhythmias in anesthetized rats and found no change [37]. Additionally one group, who earlier reported anti-arrhythmic effects in rats and rabbits, found that L-NAME had no effect on ventricular arrhythmia following $\mathrm{I} / \mathrm{R}$ in isolated marmoset hearts [38]. However, as these experiments were performed in isolated hearts and not in whole animals, certain mechanisms by which NO confers protection against arrhythmia, such as sympathetic innervation, may have been excluded. Finally, examination of the effects of resveratrol in a rodent $I / R$ model found reductions in arrhythmia, up-regulation of NOS expression and implicated NOS in resveratrol-mediated reductions in necrosis [39]. Despite this, the anti-arrhythmic effects of resveratrol were found to be NOS-independent as L-NAME could not block resveratrol-mediated reductions in arrhythmia [39]. Thus, under certain conditions, increased NO production may not confer protection against arrhythmia. Nevertheless, the majority of studies have observed an anti-arrhythmic effect by NO. In fact, NO has now been implicated as a downstream mediator of a variety of anti-arrhythmic agents including estrogen [36], erythropoietin [40], bradykinin [26], and sodium ferulate [41]. A complete list of pharmacological agents whose antiarrhythmic effects have been attributed to NO can be found in Table 1.

\section{EVIDENCE FROM GENETIC STUDIES IN ANIMALS}

A complimentary approach for determining the role of $\mathrm{NO}$ in arrhythmia is to examine the physiology of mice in which NOS isozymes have been altered. Mice deficient in NOS isozymes, as well as mice which have been modified to overexpress NOS isozymes, have dramatically advanced our understanding of NO physiology (for review see [7, 14]). These mice have the benefit of excluding any non-specific effects associated with pharmacological modification of the NOS system. Novel cardiac phenotypes have been observed in these mice which further support a protective role for NO in arrhythmia.

\section{1. eNOS}

Two studies have reported protection from arrhythmia in eNOS $^{-/-}$mice. An in vitro examination of ouabain-treated cardiomyocytes from $\mathrm{eNOS}^{-/-}$mice found that the rate of arrhythmic activity was significantly higher than in their wild-type counterparts [42]. The arrhythmic phenotype in $\mathrm{eNOS}^{-/-}$cardiomyocytes could be rescued by treatment with an NO donor. A second study examined the role of eNOS in arrhythmia in intact NOS $^{-/-}$mice [43]. While there do not appear to be any basal differences in arrhythmia between $\mathrm{eNOS}^{-/-}$mice and their wild-type counterparts, $\mathrm{eNOS}^{-/-}$mice were significantly more susceptible to digoxin-induced ventricular arrhythmias [43]. Conversely, overexpression of eNOS appears to be beneficial, as isolated cardiomyocytes from mice with cardiac-specific overexpression of eNOS exhibit a lower incidence of spontaneous arrhythmic contraction in culture than cardiomyocytes from wild-type mice [44]. Thus eNOS-derived NO appears to play a beneficial role in murine models of arrhythmia.

\section{2. nNOS}

Studies from our laboratory, and others, have suggested that $\mathrm{NO}$ derived from nNOS also plays a protective role against arrhythmia. Using isolated cardiomyocytes from $\mathrm{nNOS}^{-/-}$, eNOS ${ }^{-/-}$, and eNOS/nNOS double knockout mice, 
Table 1. Anti-Arrhythmic Agents Acting Via NO

\begin{tabular}{|l|l|l|}
\hline Agents & Animal Models & References \\
\hline \hline Bradykinin & Canine: ischemic injury & {$[26]$} \\
\hline Pirsidomine & Porcine: ischemic injury & {$[24]$} \\
\hline Sodium Ferulate & Rodent: Cultured cardiomyocytes subjected to anoxia-reoxygenation & {$[41]$} \\
\hline Pentadecapeptide BPC 157 & Rodent: digitalis-induced arrhythmia & {$[125]$} \\
\hline Erythropoietin & Murine: ischemia-reperfusion injury, cesium chloride-induced arrhythmia & {$[40]$} \\
\hline Norepinephrine & Rodent: ischemia-reperfusion injury & {$[126]$} \\
\hline 17- $\beta$ estradiol & Canine: ischemia-reperfusion injury & {$[30]$} \\
\hline Sasanquasaponin & Rodent: myocardial infarction, programmed stimulation & {$[36]$} \\
\hline $\begin{array}{l}\text { Reconstituted high density } \\
\text { lipoprotein }\end{array}$ & Rodent: ischemia-reperfusion injury & {$[104]$} \\
\hline EGB-761 & Rodent: isolated heart ischemia-reperfusion injury & {$[127]$} \\
\hline
\end{tabular}

Gonzalez et al. demonstrated that NO protects against diastolic calcium elevations and spontaneous arrhythmic contractions [45]. Interestingly, arrhythmic contractions were only observed in $\mathrm{nNOS}^{-/-}$and double-knockout cardiomyocytes suggesting that eNOS-derived NO does not confer protection against spontaneous arrhythmia in this model. Recently, we provided additional support for an antiarrhythmic role of nNOS-derived NO in mice $[40,46]$. In our study, global deletion of nNOS was associated with increased susceptibility to ventricular arrhythmia following myocardial infarction, $\mathrm{I} / \mathrm{R}$ injury, or cesium chloride infusion. Critically, we also provided evidence of increased mortality in $\mathrm{nNOS}^{-/-}$mice following myocardial infarction despite only minor differences in cardiac function [46]. Using telemetry to monitor electrocardiograms we were able to demonstrate that increased arrhythmia was directly responsible for increased mortality in this model. In addition to evidence from $\mathrm{nNOS}^{-/-}$mice, there is also indirect evidence from transgenic mice overexpressing nNOS in the heart. In these mice intracellular calcium was decreased, and adrenergic responsiveness diminished, both of which could potentially confer resistance to arrhythmia [47]. However whether nNOS overexpressing mice are resistant to arrhythmia is unclear at this time. Nevertheless, nNOSderived NO production appears to play an endogenous protective role in reducing arrhythmia and, critically, may confer protection against arrhythmia-induced mortality.

\section{3. iNOS}

Mungrue and colleagues examined cardiomyocytespecific overexpression of iNOS in mice [48]. In contrast to eNOS transgenic mice, which exhibited protection from arrhythmia, iNOS transgenic mice were found to have increased mortality and a high incidence of sudden cardiac death due to bradyarrhythmia. These results would seemingly contradict a protective role for NO in arrhythmia, however, in these mice the authors found no evidence of increased NO levels, and instead found increased $\mathrm{O}_{2}{ }^{-}$, increased peroxynitrite and NOS uncoupling. As oxidative stress has been implicated in cardiac arrhythmia [49-52], it is likely that the increased arrhythmia in these mice is a result of increased oxidative stress rather than increased NO.

\section{4. iNOS, nNOS, and eNOS}

Recently, mice deficient in all three NOS isozymes have been developed [53]. Given the possibility of compensatory up-regulation of NOS isozymes in single isoform-specific deficient mice, these triple knockout mice are uniquely suited to determining the biological effects of physiological NO production. These mice display marked reductions in survival and reproduction rates, kidney abnormalities and spontaneous myocardial infarction $[54,55]$. Interestingly, when these mice are fed a high fat diet they exhibit significant spontaneous cardiac death [56]. While the authors speculate that this sudden death may be a result of arrhythmia this was not investigated and, to date, no arrhythmic phenotype has been reported in these mice.

\section{EVIDENCE FROM HUMAN STUDIES}

Evidence is emerging that NO may confer protection from arrhythmia in the human population. A number of studies, examining gene polymorphisms, pharmacological donors, and endogenous NOS inhibitors have suggested that NO is an important protectant against arrhythmia in humans. As was seen in animal studies, nitrovasodilators appear to provide protection against arrhythmia. In patients undergoing coronary artery bypass graft, sodium nitroprusside was administered immediately following surgery (during the rewarming period) [57]. Although administered at a dose that had no effect on blood pressure or heart rate, sodium nitroprusside significantly reduced both the incidence, and the duration of atrial fibrillation (AF), which was associated with a reduction in hospital stay.

While exogenous administration of NO may provide protection against arrhythmia, there is also evidence that basal NO production itself provides protection against 
arrhythmia. Elevation in plasma levels of the endogenous NOS inhibitor asymmetric dimethylarginine (ADMA) is known to be associated with adverse cardiovascular events following cardiac [58] and non-cardiac [59] surgeries, and in patients with peripheral artery disease [60]. Recently, elevated plasma ADMA levels have been associated with increased risk of AF [61, 62]. Xia et al. reported that in patients undergoing electrical cardioversion, an elevation in pre-cardioversion ADMA was a predictor of arrhythmia recurrence [62]. The authors went on to demonstrate that treatment with rosuvastatin significantly reduces both plasma ADMA levels and recurrence of arrhythmia suggesting that enhancement of basal NO production via reductions in ADMA may provide protection against risk of arrhythmia [61]. Thus, inhibition of NOS isozymes by endogenous antagonists may be a determinant of arrhythmic susceptibility and regulation of ADMA expression may be a novel therapeutic strategy for the treatment of arrhythmia.

The gene for eNOS exhibits multiple polymorphisms in the population and the presence of certain variants can profoundly influence NO production [63]. One such polymorphism, the $-786 \mathrm{~T}>\mathrm{C}$ in the eNOS gene has been examined and the $\mathrm{C}$ allele is associated with a reduction in eNOS promoter activity and reduced NO levels in the heart $[64,65]$. This polymorphism also appears to be associated with increased risk of the development of AF [66, 67]. This risk is dramatically increased when the $-786 \mathrm{~T}>\mathrm{C}$ variant is seen in combination with an S38G polymorphism in $\operatorname{minK}$ (a gene encoding the $\beta$ subunit of the $I_{K s}$ channel) [67]. In contrast to the above studies, Bedi et al. reported that the $786 \mathrm{~T}>\mathrm{C}$ variant of eNOS was not significantly associated with AF in patients with heart failure, but that a separate eNOS genotype G894T was associated with increased risk of AF [68]. Thus certain eNOS polymorphisms may confer an increased risk of developing AF and arrhythmia. However, further study is needed to clarify whether these increases are a result of changes in endogenous NO production.

A number of reports have also identified the existence of single nucleotide polymorphisms in nNOS within the human population $[69,70]$. These polymorphisms are known to be associated with human disease conditions, such as Alzheimer's disease [71] and Parkinson's disease [69]. To date, it is unclear whether these polymorphisms are also associated with alterations in cardiac electrophysiology. However, there is indirect evidence that nNOS may play an important role in cardiac electrophysiology in the human population. Polymorphisms in the nNOS adaptor protein (NOS1AP) are associated with increased QT interval and increased risk of ventricular arrhythmia [72-77]. However, whether certain NOS1AP or NOS1 variants are at increased risk of sudden cardiac death (SCD) is not known at this time. Additionally, as NOS1AP may exert effects beyond the regulation of NOS1, it remains unclear whether nNOSderived NO is protective against arrhythmia in the human population.

Evidence is building that basal NO production plays a critical role in the prevention of ventricular and atrial arrhythmia. Moreover it is possible that modulation of endogenous inhibitors of NO production, or pharmacological treatment with NO donors may confer protection against arrhythmia in the human population. However, the role of
NO in human arrhythmia remains unclear and requires further study. Ultimately, knowledge of the relationship between NO and arrhythmia could aid in the identification of individuals who may be at increased risk of developing cardiac arrhythmia and SCD or lead to the development of novel therapeutics for the treatment of arrhythmia.

\section{PROPOSED MECHANISMS OF NO-MEDIATED CARDIOPROTECTION}

A number of downstream events have been implicated in the anti-arrhythmic effects of NO (see Fig. 1). Regulation of ion channels, gap junctions, and cell death by NO may preserve synchronous beating and conductivity. Additionally, reductions in oxidative stress-mediated arrhythmogenesis and increases in cyclic GMP-mediated signaling may also be responsible. Finally, NO may govern sympathetic nerve activity, and pulmonary vein arrhythmogenesis thereby reducing arrhythmia. Thus the anti-arrhythmic actions of NO appear to be pleiotropic, involving molecular, cellular and systemic effects.

\subsection{Ion Channel Regulation}

Several laboratories have implicated the regulation of ion channels, and in particular calcium channels, in the beneficial effects of NO $[40,45,46]$. NO can directly modulate ion channel activity through S-nitrosylation [7881], or through cyclic GMP-mediated ion channel phosphorylation [82, 83]. Sun and colleagues have reported that isolated mouse hearts treated with S-nitrosoglutathione (GSNO) or subjected to ischemic preconditioning increase S-nitrosylation of both the L-type calcium channel, and the sarcoplamic reticulum (SR) calcium ATPase [79, 84], while Gonzalez et al. have reported S-nitrosylation of the ryanodine receptor is decreased in $\mathrm{nNOS}^{-/-}$mice [45]. Our laboratory also demonstrated decreased S-nitrosylation of the L-type calcium channel, the ryanodine receptor, and the SR calcium ATPase in $\mathrm{nNOS}^{-/-}$mice [46]. These changes were associated with diastolic calcium elevations, ventricular arrhythmia and sudden cardiac death. In addition to the effects on calcium handling proteins, NO has also been reported to play a role in the regulation of sodium, and potassium channels, which may also play a role in protection of arrhythmia [85-87]. The cardiac $\mathrm{Na} / \mathrm{K}$-ATPase appears to be activated by $\mathrm{NO}$, and $\mathrm{NO}$ has been reported to preserve $\mathrm{Na} / \mathrm{K}-\mathrm{ATPase}$ activity during ischemia [88], which may limit calcium elevations in cardiomyocytes. A brief summary of ion channel regulation by NO is provided in Fig. (2). For a more comprehensive examination of the role of NO in the regulation of cardiac ion channels readers are directed to a recent review by Tamargo and colleagues [89].

\subsection{Cyclic GMP}

The common downstream effector of NO, cyclic GMP (cGMP) has also been implicated in mediating the effects of NO on arrhythmia. cGMP has been shown to mimic the antiarrhythmic effects of NO in ouabain-treated mouse cardiomyocytes [42]. Additionally, Chen et al. examined the anti-arrhythmic effects of sodium ferulate in isolated rat cardiomyocytes subjected to anoxia-reoxygenation [41]. Treatment with sodium ferulate was associated with increases in NO and cyclic GMP, and inhibition of either NO or cGMP blocked the effects of sodium ferulate on calcium 


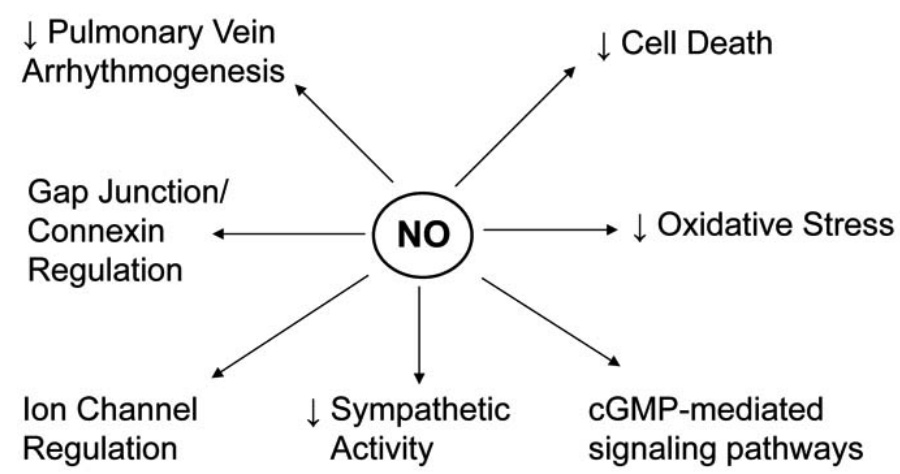

Fig. (1). Putative mechanisms by which NO mediates protection against cardiac arrhythmia. cGMP, cyclic guanylyl monophosphate; NO, nitric oxide.

overload and arrhythmogenesis induced by anoxiareoxygenation. While it is conceivable that cGMP mediates these effects through changes in ion channels, one cannot rule out the possibility of cGMP-independent regulation of ion channels. Further study is required to clarify the role of cGMP in mediating the anti-arrhythmic effects of NO.

\subsection{Gap Junction Regulation}

Connexin 43 is a major component of ventricular gap junctions, and an important determinant of impulse conduction. Loss of connexin 43 is associated with a significant increase in ventricular arrhythmias and risk of sudden cardiac death [90-92]. Two separate laboratories have demonstrated that NO is capable of preserving connexin 43 and gap junction activity. Gonczi and colleagues demonstrated that sodium nitroprusside reduces I/R-induced arrhythmia in dogs and preserves both connexin 43 phosphorylation and gap junction permeability [93]. Chen et al. correlated estrogenmediated reductions in arrhythmia with preservation of connexin 43 expression and demonstrated that this preservation may be NO-dependent [36]. However, at higher concentrations, such as those seen with iNOS expression, NO may actually contribute to down-regulation of connexin, as we have shown that iNOS-derived NO production resulted in reductions in myocardial connexin 43 expression [94]. Thus NO-mediated regulation of connexin 43 and gap junctions may be isoform- and/or concentration-dependent. Interestingly, NO has been reported to promote de novo formation of endothelial gap junctions [95]. Whether a similar pathway exists in cardiomyocytes, and whether this pathway plays a role in cardiac arrhythmia remains to be elucidated.

\subsection{Oxidative Stress}

There is growing evidence of a role for oxidative stress in the induction of arrhythmia. While excess activation of NOS, such as that seen in iNOS transgenic mice that were prone to arrhythmia and sudden cardiac death, can lead to NOS uncoupling and oxidative stress, physiological NO production has been shown to inhibit ROS production [96-100]. Given the well established role for oxidative stress in the pathogenesis and maintenance of arrhythmia [101], and the mounting evidence that antioxidants are effective in arrhythmia [102], reductions in oxidative stress represent a potential mechanism by which NO prevents arrhythmia. Recently, NO-mediated reductions in $\mathrm{O}_{2}^{-}$have been implicated in preconditioning-mediated protection from arrhythmia in dogs [103]. Additionally, two studies have provided indirect evidence of a role for reductions in oxidative stress in the anti-arrhythmic effects of NO. When examining the antiarrhythmic effects of sasanquasaponin (the active component of the Chinese herbal remedy Camellia oleifera Abel), Liao et $a l$. found reductions in arrhythmia were associated with both increased NO production and decreased oxidative stress [104]. Additionally, when examining the anti-arrhythmic effects of sodium nitroprusside, Cavolli et al. found reductions in C-reactive protein levels, an index of inflammation which frequently correlates with oxidative stress [105]. Nevertheless, a direct causal link between NO, the reduction in oxidative stress, and protection from arrhythmia has not been established.

\subsection{Regulation of Ischemic Injury/Cell Death}

Physiological NO production is also known to play a protective role in the prevention of apoptotic cell death and ischemic injury [13, 106, 107]. Reductions in apoptosis and ischemic injury preserve cardiac function and protect against ventricular remodeling, these actions may also preserve conductivity in the heart and prevent arrhythmia [108]. Numerous studies have shown that NO prevents arrhythmogenesis at the single cell level [23, 41, 45, 109], suggesting that reduction of apoptosis/ischemic injury is not the sole mediator of the anti-arrhythmic effects of NO. However given the close relationship between myocardial damage and electrical conductivity, one cannot rule out the possibility that cardioprotection contributes to the antiarrhythmic effects of NO.

\subsection{Regulation of Sympathetic Activity}

It has also been proposed that NO may mediate its antiarrhythmic effects through alteration of sympathetic nerve activity [110]. NO, particularly that derived from nNOS, exerts significant sympatholytic effects [111-113]. As excess sympathetic activity may play a role in the induction of ventricular arrhythmia, alterations in sympathetic activity may be a mechanism by which NO protects against arrhythmia. However, similar to effects on apoptosis/ischemic injury, the observation that NO has anti-arrhythmic effects in isolated myocytes suggests that this is not the sole mediator of NOmediated protection.

\subsection{Pulmonary Vein Arrhythmogenesis}

Finally, a role for NO in the control of pulmonary vein arrhythmogenesis has recently been identified. The pulmonary veins are a critical source for the initiation of 


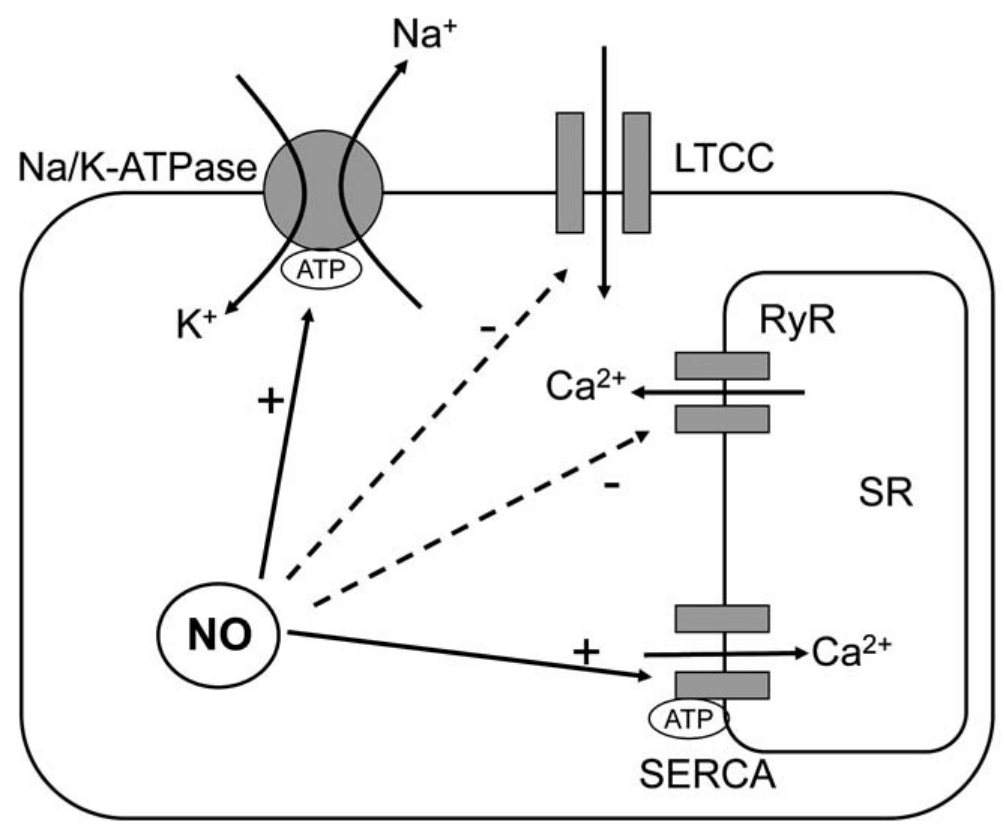

Fig. (2). Regulation of ion channel activity in cardiomyocytes by NO. SR, sarcoplasmic reticulum; SERCA, SR-Ca ${ }^{2+}$ ATPase; RyR, ryanodine receptor; LTCC, L-type $\mathrm{Ca}^{2+}$

atrial arrhythmias as evidenced by the fact that radio frequency ablation of areas adjacent to the pulmonary veins results in a dramatic reduction in arrhythmia and AF [114, 115]. Furthermore, Lin et al. found that exogenous NO (in the form of sodium nitroprusside) reduced spontaneous electrical activity, and inhibited delayed afterdepolarizations in cardiomyocytes isolated from regions adjacent to pulmonary vein [109]. A second study, examining pulmonary vein activity in rabbits found that fluvastatin reduced spontaneous pulmonary vein activity in a NOSdependent manner [116]. These observations raise the possibility that the pulmonary veins, a critical source of arrhythmogenesis, may be inhibited pharmacologically through modulation of NO.

In summary, there are several mechanisms by which NO may confer protection from arrhythmia, including the regulation of gap junctions, ion channel activity, modulation of ischemic injury or sympathetic outflow and reductions in oxidative stress. Given the diverse range of biological processes that are regulated by $\mathrm{NO}$ it is not surprising that such a diverse range of downstream events have been implicated in NO-mediated protection from arrhythmia. Ultimately, it is likely that NO-mediated protection from arrhythmia is mediated through several, complementary mechanisms.

\section{PERSPECTIVES AND CONCLUSIONS}

Evidence is mounting that NO plays an important endogenous regulatory role in cardiac electrophysiology. Several lines of pharmacological and genetic evidence from both animal and human studies point to NO playing a protective role preventing arrhythmogenesis. Multiple mechanisms have been proposed to mediate the anti-arrhythmic effects of NO and these effects are likely a coordinated action on several systems.
One interesting finding is the observation that eNOS expression decreases during AF [117, 118]. Laminar blood flow and shear stress is a critical determinant of both eNOS expression [119-121] and activity of the NOS co-factor tetrahydrobiopterin [122, 123]. Arrhythmic contractions in the heart can produce a more turbulent blood flow, which could potentially reduce NOS expression [124]. This raises the interesting possibility that reductions in NO production may facilitate the propagation of arrhythmia. An initial arrhythmic insult would thus prime the heart for further arrhythmic activity by decreasing eNOS-derived NO, thereby reducing the body's endogenous ability to suppress arrhythmia in a feed forward fashion.

Despite the abundance of data suggesting a role for $\mathrm{NO}$ in cardiac arrhythmia, clarification is needed relating to the source and amount of NO that confers protection from arrhythmia. As mentioned previously, in certain species nNOS appears to be the major NOS isozyme conferring protection against arrhythmia, while other NOS isozymes may be responsible in other species [28]. Additionally, in other experimental paradigms NO production can be either beneficial or deleterious depending on the isozyme and the amount of NO produced. For example, while high levels of NO produced by iNOS may promote cardiomyocyte apoptosis, low levels of NO produced by eNOS may actually protect against apoptosis [13]. With respect to the effects of NO in arrhythmia, mice overexpressing iNOS are actually more susceptible to SCD due to arrhythmia [48]. While this effect has been attributed to production of $\mathrm{O}_{2}^{-}$rather than $\mathrm{NO}$ in these mice, it is possible that excess production of NO by iNOS does not provide the same cardioprotection as that conferred by eNOS or nNOS-derived NO. In fact, contrary to eNOS and nNOS, where models of genetic deletion have suggested susceptibility to arrhythmia, there is no direct evidence that NO production by iNOS provides any protection against arrhythmia. A study by Rickover et al. further suggests that the amount of NO produced is critical to its anti-arrhythmic 
effects [23]. In this study low doses of sodium nitroprusside $(0.1 \mathrm{mM})$ provided protection against hypoxia-induced arrhythmogenic beating in cultured rat cardiomyocytes. However, high doses (5-10 $\mathrm{mM})$ actually elevated intracellular $\mathrm{Ca}^{2+}$ levels and accelerated cardiomyocyte beating. Thus the level of NO produced may be a critical determinant of its ability to provide protection against arrhythmia and caution must be exercised in any approach to treat arrhythmia with nitrovasodilators, or NO donors.

There is now abundant evidence that NO is capable of providing protection against atrial and ventricular arrhythmia in several animal models and in humans. Although our understanding of the mechanisms by which NO achieves this protection is still developing, the regulation of ion channel function, sympathetic activity, gap junction expression, cell death, cGMP, and alterations in pulmonary vein arrhythmogenesis have been implicated (Figs. 1 and 2). The presence of an endogenous protective system involving NOmediated reductions in arrhythmia is clear, and may partially explain generation and/or propagation of arrhythmia during disease conditions where NO production is altered. Pharmacological modulation of this system appears to protect against arrhythmia. However, further studies on the role of NO in arrhythmia are necessary and safe doses of NO donors need to be established from clinical trials for therapeutic applications in patients with arrhythmia.

\section{ACKNOWLEDGEMENTS}

Work in Dr. Feng laboratory is currently supported by Canadian Institutes of Health Research (CIHR) and the Heart and Stroke Foundation of Ontario (HSFO). D.B. is supported through a KRESCENT Research fellowship. Q.F. is a HSFO Career Investigator.

\section{CONFLICT OF INTEREST}

None.

\section{REFERENCES}

[1] Ignarro, L.J.; Buga, G.M.; Wood, K.S.; Byrns, R.E.; Chaudhuri, G. Endothelium-derived relaxing factor produced and released from artery and vein is nitric oxide. Proc. Natl. Acad. Sci. U S A, 1987, 84, 9265-9269.

[2] Furchgott, R.F.; Zawadzki, J.V. The obligatory role of endothelial cells in the relaxation of arterial smooth muscle by acetylcholine. Nature, 1980, 288, 373-376.

[3] Arnold, W.P.; Mittal, C.K.; Katsuki, S.; Murad, F. Nitric oxide activates guanylate cyclase and increases guanosine $3^{\prime}: 5^{\prime}$-cyclic monophosphate levels in various tissue preparations. Proc. Natl. Acad. Sci. U S A, 1977, 74, 3203-3207.

[4] Palmer, R.M.; Ferrige, A.G.; Moncada, S. Nitric oxide release accounts for the biological activity of endothelium-derived relaxing factor. Nature., 1987, 327, 524-526.

[5] Katsuki, S.; Arnold, W.; Mittal, C.; Murad, F. Stimulation of guanylate cyclase by sodium nitroprusside, nitroglycerin and nitric oxide in various tissue preparations and comparison to the effects of sodium azide and hydroxylamine. J. Cyclic Nucleotide Res., 1977, 3, 23-35.

[6] Bredt, D.S. Endogenous nitric oxide synthesis: biological functions and pathophysiology. Free Radic. Res., 1999, 31, 577-596.

[7] Liu, V.W.; Huang, P.L. Cardiovascular roles of nitric oxide: a review of insights from nitric oxide synthase gene disrupted mice. Cardiovasc. Res., 2008, 77, 19-29.

[8] Mungrue, I.N.; Bredt, D.S.; Stewart, D.J.; Husain, M. From molecules to mammals: what's NOS got to do with it? Acta. Physiol. Scand., 2003, 179, 123-135.
[9] Lundberg, J.O.; Weitzberg, E. NO-synthase independent NO generation in mammals. Biochem. Biophys. Res. Commun., 2010, 396, $39-45$.

[10] Kapil, V.; Webb, A.J.; Ahluwalia, A. Inorganic nitrate and the cardiovascular system. Heart., 2010; 96(21): 1703-1709.

[11] Webb, A.J.; Milsom, A.B.; Rathod, K.S.; Chu, W.L.; Qureshi, S.; Lovell, M.J.; Lecomte, F.M.; Perrett, D.; Raimondo, C.; Khoshbin, E.; Ahmed, Z.; Uppal, R.; Benjamin, N.; Hobbs, A.J.; Ahluwalia, A. Mechanisms underlying erythrocyte and endothelial nitrite reduction to nitric oxide in hypoxia: role for xanthine oxidoreductase and endothelial nitric oxide synthase. Circ Res., 2008, 103, 957964.

[12] Mungrue, I.N.; Husain, M.; Stewart, D.J. The role of NOS in heart failure: lessons from murine genetic models. Heart Fail. Rev. 2002, 7, 407-422.

[13] Razavi, H.M.; Hamilton, J.A.; Feng, Q. Modulation of apoptosis by nitric oxide: implications in myocardial ischemia and heart failure. Pharmacol. Ther., 2005, 106, 147-162.

[14] Tsutsui, M.; Shimokawa, H.; Otsuji, Y.; Yanagihara, N. Pathophysiological relevance of NO signaling in the cardiovascular system: Novel insight from mice lacking all NO synthases. Pharmacol. Ther., 2010: 128(3), 499-508.

[15] Shimokawa, H.; Tsutsui, M. Nitric oxide synthases in the pathogenesis of cardiovascular disease: lessons from genetically modified mice. Pflugers. Arch., 2010, 459, 959-967.

[16] Casadei, B. The emerging role of neuronal nitric oxide synthase in the regulation of myocardial function. Exp. Physiol., 2006, 91, 943955.

[17] Kent, K.M.; Smith, E.R.; Redwood, D.R.; Epstein, S.E. Beneficial electrophysiologic effects of nitroglycerin during acute myocardial infarction. Am. J. Cardiol., 1974, 33, 513-516.

[18] Borer, J.S.; Kent, K.M.; Goldstein, R.E.; Epstein, S.E. Nitroglycerin-induced reduction in the incidence of spontaneous ventricular fibrillation during coronary occlusion in dogs. Am. J. Cardiol., 1974, 33, 517-520.

[19] Knoebel, S.B.; Rasmussen, S.; Noble, R.J.; Mihalick, M.J. Nitroglycerin and premature ventricular complexes in myocardial infarction. Br. Heart J., 1975, 37, 1064-1068.

[20] Gagnon, R.M.; Lemire, J.; Beaudet, R. Intravenous use of nitroglycerin to control severe ventricular arrhythmias in unstable angina. Can. Med. Assoc. J., 1980, 123, 1131-1133.

[21] Mukherjee, D.; Feldman, M.S.; Helfant, R.H. Nitroprusside therapy. Treatment of hypertensive patients with recurrent resting chest pain, ST-segment elevation, and ventricular arrhythmias. JAMA., 1976, 235, 2406-2409.

[22] Lascano, E.C.; Valle, H.F.; Negroni, J.A. Nitroglycerin induces late preconditioning against arrhythmias but not stunning in conscious sheep. Scand. Cardiovasc. J., 2007, 41, 160-166.

[23] Rickover, O.; Zinman, T.; Kaplan, D.; Shainberg, A. Exogenous nitric oxide triggers classic ischemic preconditioning by preventing intracellular $\mathrm{Ca} 2+$ overload in cardiomyocytes. Cell. Calcium, 2008, 43, 324-333.

[24] Wainwright, C.L.; Martorana, P.A. Pirsidomine, a novel nitric oxide donor, suppresses ischemic arrhythmias in anesthetized pigs. J. Cardiovasc. Pharmacol., 1993, 22 (Supp1 7), S44-S50.

[25] Vegh, A.; Szekeres, L.; Parratt, J. Preconditioning of the ischaemic myocardium; involvement of the L-arginine nitric oxide pathway. Br. J. Pharmacol., 1992, 107, 648-652.

[26] Vegh, A.; Papp, J.G.; Szekeres, L.; Parratt, J.R. Prevention by an inhibitor of the L-arginine-nitric oxide pathway of the antiarrhythmic effects of bradykinin in anaesthetized dogs. Br. J. Pharmacol., 1993, 110, 18-9.

[27] Pabla, R.; Curtis, M.J. Effects of NO modulation on cardiac arrhythmias in the rat isolated heart. Circ. Res, 1995, 77, 984-992.

[28] Pabla, R.; Curtis, M.J. Endogenous protection against reperfusioninduced ventricular fibrillation: role of neuronal versus nonneuronal sources of nitric oxide and species dependence in the rat versus rabbit isolated heart. J. Mol. Cell. Cardiol., 1996, 28, 20972110.

[29] Healy, C.; Milmore, J.E.; Guideri, G. Effects of ethinyl estradiol on isoproterenol-induced death in ventricular fibrillation in DOCA-salt pretreated male and female rats. Life Sci., 1991, 48, 1931-1936.

[30] Kim, Y.D.; Chen, B.; Beauregard, J.; Kouretas, P.; Thomas, G.; Farhat, M.Y.; Myers, A.K.; Lees, D.E. 17 beta-Estradiol prevents dysfunction of canine coronary endothelium and myocardium and 
reperfusion arrhythmias after brief ischemia/reperfusion. Circulation, 1996, 94, 2901-2908.

[31] McHugh, N.A.; Cook, S.M.; Schairer, J.L.; Bidgoli, M.M.; Merrill, G.F. Ischemia- and reperfusion-induced ventricular arrhythmias in dogs: effects of estrogen. Am. J. Physiol., 1995, 268, H2569H2573.

[32] Nakajima, T.; Iwasawa, K.; Oonuma, H.; Morita, T.; Goto, A.; Wang, Y.; Hazama, H. Antiarrhythmic effect and its underlying ionic mechanism of 17 beta-estradiol in cardiac myocytes. Br. J. Pharmacol., 1999, 127, 429-440.

[33] Humphreys, R.A.; Kane, K.A.; Parratt, J.R. The influence of maturation and gender on the anti-arrhythmic effect of ischaemic preconditioning in rats. Basic Res. Cardiol., 1999, 94, 1-8.

[34] Das, B.; Sarkar, C. Similarities between ischemic preconditioning and 17 beta-estradiol mediated cardiomyocyte KATP channel activation leading to cardioprotective and antiarrhythmic effects during ischemia/reperfusion in the intact rabbit heart. J. Cardiovasc. Pharmacol., 2006, 47, 277-286.

[35] Node, K.; Kitakaze, M.; Kosaka, H.; Minamino, T.; Funaya, H.; Hori, M. Amelioration of ischemia- and reperfusion-induced myocardial injury by 17 beta-estradiol: role of nitric oxide and calciumactivated potassium channels. Circulation., 1997, 96, 1953-1963.

[36] Chen, C.C.; Lin, C.C.; Lee, T.M. 17beta-Estradiol decreases vulnerability to ventricular arrhythmias by preserving connexin43 protein in infarcted rats. Eur. J. Pharmacol., 2010, 629, 73-81.

[37] Barnes, C.S.; Coker, S.J. Failure of nitric oxide donors to alter arrhythmias induced by acute myocardial ischaemia or reperfusion in anaesthetized rats. Br. J. Pharmacol., 1995, 114, 349-356.

[38] Pabla, R.; Curtis, M.J. Nitric oxide fails to confer endogenous antiarrhythmic cardioprotection in the primate heart in vitro. Br. J. Pharmacol., 2007, 150, 893-898.

[39] Hung, L.M.; Su, M.J.; Chen, J.K. Resveratrol protects myocardial ischemia-reperfusion injury through both NO-dependent and NOindependent mechanisms. Free Radic. Biol. Med., 2004, 36, 774781.

[40] Burger, D.E.; Xiang, F.L.; Hammoud, L.; Jones, D.L.; Feng, Q. Erythropoietin protects the heart from ventricular arrhythmia during ischemia and reperfusion via neuronal nitric-oxide synthase. $J$. Pharmacol. Exp. Ther., 2009, 329, 900-907.

[41] Chen, H.P.; Liao, Z.P.; Huang, Q.R.; He, M. Sodium ferulate attenuates anoxia/reoxygenation-induced calcium overload in neonatal rat cardiomyocytes by NO/cGMP/PKG pathway. Eur. J. Pharmacol., 2009, 603, 86-92.

[42] Kubota, I.; Han, X.; Opel, D.J.; Zhao, Y.Y.; Baliga, R.; Huang, P.; Fishman, M.C.; Shannon, R.P.; Michel, T.; Kelly, R.A. Increased susceptibility to development of triggered activity in myocytes from mice with targeted disruption of endothelial nitric oxide synthase. J. Mol. Cell. Cardiol., 2000, 32, 1239-1248.

[43] Rakhit, A.; Maguire, C.T.; Wakimoto, H.; Gehrmann, J.; Li, G.K.; Kelly, R.A.; Michel, T.; Berul, C.I. In vivo electrophysiologic studies in endothelial nitric oxide synthase (eNOS)-deficient mice. $J$. Cardiovasc. Electrophysiol., 2001, 12, 1295-1301.

[44] Massion, P.B.; Dessy, C.; Desjardins, F.; Pelat, M.; Havaux, X.; Belge, C.; Moulin, P.; Guiot, Y.; Feron, O.; Janssens, S.; Balligand, J.L. Cardiomyocyte-restricted overexpression of endothelial nitric oxide synthase (NOS3) attenuates beta-adrenergic stimulation and reinforces vagal inhibition of cardiac contraction. Circulation, 2004, 110, 2666-2672.

[45] Gonzalez, D.R.; Beigi, F.; Treuer, A.V.; Hare, J.M. Deficient ryanodine receptor S-nitrosylation increases sarcoplasmic reticulum calcium leak and arrhythmogenesis in cardiomyocytes. Proc. Natl. Acad. Sci.U S A., 2007, 104, 20612-20617.

[46] Burger, D.E.; Lu, X.; Lei, M.; Xiang, F.L.; Hammoud, L.; Jiang, M.; Wang, H.; Jones, D.L.; Sims, S.M.; Feng, Q. Neuronal nitric oxide synthase protects against myocardial infarction-induced ventricular arrhythmia and mortality in mice. Circulation, 2009, 120, 1345-1354.

[47] Burkard, N.; Rokita, A.G.; Kaufmann, S.G.; Hallhuber, M.; Wu, R.; Hu, K.; Hofmann, U.; Bonz, A.; Frantz, S.; Cartwright, E.J.; Neyses, L.; Maier, L.S.; Maier, S.K.; Renne, T.; Schuh, K.; Ritter, O. Conditional neuronal nitric oxide synthase overexpression impairs myocardial contractility. Circ. Res., 2007, 100, e32-44.

[48] Mungrue, I.N.; Gros, R.; You, X.; Pirani, A.; Azad, A.; Csont, T.; Schulz, R.; Butany, J.; Stewart, D.J.; Husain, M. Cardiomyocyte overexpression of iNOS in mice results in peroxynitrite generation, heart block, and sudden death. J.Clin. Invest., 2002, 109, 735-743.
[49] Kim, Y.M.; Kattach, H.; Ratnatunga, C.; Pillai, R.; Channon, K.M.; Casadei, B. Association of atrial nicotinamide adenine dinucleotide phosphate oxidase activity with the development of atrial fibrillation after cardiac surgery. J. Am. Coll. Cardiol., 2008, 51, 68-74.

[50] Morita, N.; Sovari, A.A.; Xie, Y.; Fishbein, M.C.; Mandel, W.J.; Garfinkel, A.; Lin, S.F.; Chen, P.S.; Xie, L.H.; Chen, F.; Qu, Z.; Weiss, J.N.; Karagueuzian, H.S. Increased susceptibility of aged hearts to ventricular fibrillation during oxidative stress. Am. J. Physiol. Heart. Circ. Physiol., 2009, 297, H1594-605.

[51] Liu, X.; Tosaki, A.; Engelman, R.M.; Das, D.K. Reduction of postischaemic ventricular dysfunction and arrhythmias by trapping hydroxyl radicals with salicylic acid. Int. J. Tissue React., 1993, 15, 25-30.

[52] Lin, Y.K.; Lin, F.Z.; Chen, Y.C.; Cheng, C.C.; Lin, C.I.; Chen, Y.J.; Chen, S.A. Oxidative stress on pulmonary vein and left atrium arrhythmogenesis. Circ. J., 2010, 74, 1547-1556.

[53] Tsutsui, M.; Shimokawa, H.; Morishita, T.; Nakata, S.; Sabanai, K.; Nakashima, Y.; Yanagihara, N. Development of genetically engineered mice lacking all three nitric oxide synthase isoforms. $\mathrm{Ya}$ kugaku Zasshi, 2007, 127, 1347-1355.

[54] Nakata, S.; Tsutsui, M.; Shimokawa, H.; Suda, O.; Morishita, T.; Shibata, K.; Yatera, Y.; Sabanai, K.; Tanimoto, A.; Nagasaki, M.; Tasaki, H.; Sasaguri, Y.; Nakashima, Y.; Otsuji, Y.; Yanagihara, N. Spontaneous myocardial infarction in mice lacking all nitric oxide synthase isoforms. Circulation., 2008, 117, 2211-2223.

[55] Morishita, T.; Tsutsui, M.; Shimokawa, H.; Sabanai, K.; Tasaki, H.; Suda, O.; Nakata, S.; Tanimoto, A.; Wang, K.Y.; Ueta, Y.; Sasaguri, Y.; Nakashima, Y.; Yanagihara, N. Nephrogenic diabetes insipidus in mice lacking all nitric oxide synthase isoforms. Proc. Natl. Acad. Sci. U. S. A, 2005, 102, 10616-10621.

[56] Yatera, Y.; Shibata, K.; Furuno, Y.; Sabanai, K.; Morisada, N.; Nakata, S.; Morishita, T.; Toyohira, Y.; Wang, K.Y.; Tanimoto, A.; Sasaguri, Y.; Tasaki, H.; Nakashima, Y.; Shimokawa, H.; Yanagihara, N.; Otsuji, Y.; Tsutsui, M. Severe dyslipidaemia, atherosclerosis, and sudden cardiac death in mice lacking all NO synthases fed a high-fat diet. Cardiovasc. Res., 2010, 87, 675-682.

[57] Cavolli, R.; Kaya, K.; Aslan, A.; Emiroglu, O.; Erturk, S.; Korkmaz, O.; Oguz, M.; Tasoz, R.; Ozyurda, U. Does sodium nitroprusside decrease the incidence of atrial fibrillation after myocardial revascularization?: a pilot study. Circulation, 2008, 118, 476-481.

[58] Lu, T.M.; Ding, Y.A.; Lin, S.J.; Lee, W.S.; Tai, H.C. Plasma levels of asymmetrical dimethylarginine and adverse cardiovascular events after percutaneous coronary intervention. Eur. Heart J., 2003, 24, 1912-1919.

[59] Maas, R.; Dentz, L.; Schwedhelm, E.; Thoms, W.; Kuss, O.; Hiltmeyer, N.; Haddad, M.; Kloss, T.; Standl, T.; Boger, R.H. Elevated plasma concentrations of the endogenous nitric oxide synthase inhibitor asymmetric dimethylarginine predict adverse events in patients undergoing noncardiac surgery. Crit. Care Med., 2007, 35, 1876-1881.

[60] Mittermayer, F.; Krzyzanowska, K.; Exner, M.; Mlekusch, W.; Amighi, J.; Sabeti, S.; Minar, E.; Muller, M.; Wolzt, M.; Schillinger, M. Asymmetric dimethylarginine predicts major adverse cardiovascular events in patients with advanced peripheral artery disease. Arterioscler. Thromb. Vasc. Biol., 2006, 26, 2536-2540.

[61] Xia, W.; Yin, Z.; Li, J.; Song, Y.; Qu, X. Effects of rosuvastatin on asymmetric dimethylarginine levels and early atrial fibrillation recurrence after electrical cardioversion. Pacing Clin. Electrophysiol., 2009, 32, 1562-1566.

[62] Xia, W.; Qu, X.; Yu, Y.; Zhang, X.; Feng, W.; Song, Y. Asymmetric dimethylarginine concentration and early recurrence of atrial fibrillation after electrical cardioversion. Pacing Clin. Electrophysiol., 2008, 31, 1036-1040.

[63] Wang, X.L.; Mahaney, M.C.; Sim, A.S.; Wang, J.; Blangero, J.; Almasy, L.; Badenhop, R.B.; Wilcken, D.E. Genetic contribution of the endothelial constitutive nitric oxide synthase gene to plasma nitric oxide levels. Arterioscler. Thromb. Vasc. Biol., 1997, 17, 3147-3153.

[64] Nakayama, M.; Yasue, H.; Yoshimura, M.; Shimasaki, Y.; Kugiyama, K.; Ogawa, H.; Motoyama, T.; Saito, Y.; Ogawa, Y.; Miyamoto, Y.; Nakao, K. T-786-->C mutation in the 5'-flanking region of the endothelial nitric oxide synthase gene is associated with coronary spasm. Circulation, 1999, 99, 2864-2870.

[65] Nakayama, M.; Yoshimura, M.; Sakamoto, T.; Abe, K.; Yamamuro, M.; Shono, M.; Suzuki, S.; Nishijima, T.; Miyamoto, Y.; Saito, Y.; Nakao, K.; Yasue, H.; Ogawa, H. A -786T $>$ C poly- 
morphism in the endothelial nitric oxide synthase gene reduces serum nitrite/nitrate levels from the heart due to an intracoronary injection of acetylcholine. Pharmacogenet. Genomics., 2006, 16, 339-345.

[66] Giusti, B.; Gori, A.M.; Marcucci, R.; Sestini, I.; Saracini, C.; Sticchi, E.; Gensini, F.; Fatini, C.; Abbate, R.; Gensini, G.F. Role of C677T and A1298C MTHFR, A2756G MTR and -786 C/T eNOS gene polymorphisms in atrial fibrillation susceptibility. PLoS One, 2007, 2, e495.

[67] Fatini, C.; Sticchi, E.; Genuardi, M.; Sofi, F.; Gensini, F.; Gori, A.M.; Lenti, M.; Michelucci, A.; Abbate, R.; Gensini, G.F. Analysis of $\operatorname{minK}$ and eNOS genes as candidate loci for predisposition to non-valvular atrial fibrillation. Eur. Heart J., 2006, 27, 1712-1718.

[68] Bedi, M.; McNamara, D.; London, B.; Schwartzman, D. Genetic susceptibility to atrial fibrillation in patients with congestive heart failure. Heart Rhythm., 2006, 3, 808-812.

[69] Levecque, C.; Elbaz, A.; Clavel, J.; Richard, F.; Vidal, J.S.; Amouyel, P.; Tzourio, C.; Alperovitch, A.; Chartier-Harlin, M.C. Association between Parkinson's disease and polymorphisms in the nNOS and iNOS genes in a community-based case-control study. Hum. Mol. Genet., 2003, 12, 79-86.

[70] Venturelli, E.; Villa, C.; Scarpini, E.; Fenoglio, C.; Guidi, I.; Lovati, C.; Marcone, A.; Cortini, F.; Scalabrini, D.; Clerici, F.; Bresolin, N.; Mariani, C.; Cappa, S.; Galimberti, D. Neuronal nitric oxide synthase $\mathrm{C} 276 \mathrm{~T}$ polymorphism increases the risk for frontotemporal lobar degeneration. Eur. J. Neurol., 2008, 15, 77-81.

[71] Galimberti, D.; Venturelli, E.; Gatti, A.; Lovati, C.; Fenoglio, C.; Mariani, C.; Forloni, G.; Bresolin, N.; Scarpini, E. Association of neuronal nitric oxide synthase $\mathrm{C} 276 \mathrm{~T}$ polymorphism with Alzheimer's disease. J. Neurol., 2005, 252, 985-986.

[72] Aarnoudse, A.J.; Newton-Cheh, C.; de Bakker, P.I.; Straus, S.M.; Kors, J.A.; Hofman, A.; Uitterlinden, A.G.; Witteman, J.C.; Stricker, B.H. Common NOS1AP variants are associated with a prolonged QTc interval in the Rotterdam Study. Circulation, 2007, $116,10-6$.

[73] Arking, D.E.; Pfeufer, A.; Post, W.; Kao, W.H.; Newton-Cheh, C.; Ikeda, M.; West, K.; Kashuk, C.; Akyol, M.; Perz, S.; Jalilzadeh, S.; Illig, T.; Gieger, C.; Guo, C.Y.; Larson, M.G.; Wichmann, H.E.; Marban, E.; O'Donnell, C.J.; Hirschhorn, J.N.; Kaab, S.; Spooner, P.M.; Meitinger, T.; Chakravarti, A. A common genetic variant in the NOS1 regulator NOS1AP modulates cardiac repolarization. Nat. Genet., 2006, 38, 644-651.

[74] Lehtinen, A.B.; Newton-Cheh, C.; Ziegler, J.T.; Langefeld, C.D.; Freedman, B.I.; Daniel, K.R.; Herrington, D.M.; Bowden, D.W. Association of NOS1AP genetic variants with QT interval duration in families from the Diabetes Heart Study. Diabetes, 2008, 57, 1108-1114.

[75] Tobin, M.D.; Kahonen, M.; Braund, P.; Nieminen, T.; Hajat, C.; Tomaszewski, M.; Viik, J.; Lehtinen, R.; Ng, G.A.; Macfarlane, P.W.; Burton, P.R.; Lehtimaki, T.; Samani, N.J. Gender and effects of a common genetic variant in the NOS1 regulator NOS1AP on cardiac repolarization in 3761 individuals from two independent populations. Int. J. Epidemiol., 2008, 37, 1132-1141.

[76] Eijgelsheim, M.; Aarnoudse, A.L.; Rivadeneira, F.; Kors, J.A.; Witteman, J.C.; Hofman, A.; van Duijn, C.M.; Uitterlinden, A.G.; Stricker, B.H. Identification of a common variant at the NOS1AP locus strongly associated to QT-interval duration. Hum. Mol. Genet., 2009, 18, 347-357.

[77] Crotti, L.; Monti, M.C.; Insolia, R.; Peljto, A.; Goosen, A.; Brink, P.A.; Greenberg, D.A.; Schwartz, P.J.; George, A.L., Jr. NOS1AP is a genetic modifier of the long-QT syndrome. Circulation, 2009, $120,1657-1663$

[78] Sun, J.; Steenbergen, C.; Murphy, E. S-nitrosylation: NO-related redox signaling to protect against oxidative stress. Antioxid. Redox. Signal, 2006, 8, 1693-1705.

[79] Sun, J.; Morgan, M.; Shen, R.F.; Steenbergen, C.; Murphy, E. Preconditioning results in S-nitrosylation of proteins involved in regulation of mitochondrial energetics and calcium transport. Circ. Res., 2007, 101, 1155-1563.

[80] Sun, J.; Murphy, E. Protein S-nitrosylation and cardioprotection. Circ. Res., 2010, 106, 285-296.

[81] Wang, H.; Viatchenko-Karpinski, S.; Sun, J.; Gyorke, I.; Benkusky, N.A.; Kohr, M.J.; Valdivia, H.H.; Murphy, E.; Gyorke, S.; Ziolo, M.T. Regulation of myocyte contraction via neuronal nitric oxide synthase: role of ryanodine receptor S-nitrosylation. $J$. Physiol., 2010, 588, 2905-2917.
[82] Bai, C.X.; Takahashi, K.; Masumiya, H.; Sawanobori, T.; Furukawa, T. Nitric oxide-dependent modulation of the delayed rectifier $\mathrm{K}+$ current and the L-type $\mathrm{Ca} 2+$ current by ginsenoside $\mathrm{Re}$, an ingredient of Panax ginseng, in guinea-pig cardiomyocytes. $\mathrm{Br} . J$. Pharmacol., 2004, 142, 567-575.

[83] Gonzalez, D.R.; Fernandez, I.C.; Ordenes, P.P.; Treuer, A.V.; Eller, G.; Boric, M.P. Differential role of S-nitrosylation and the NO-cGMP-PKG pathway in cardiac contractility. Nitric Oxide, 2008, 18, 157-167.

[84] Sun, J.; Picht, E.; Ginsburg, K.S.; Bers, D.M.; Steenbergen, C.; Murphy, E. Hypercontractile female hearts exhibit increased Snitrosylation of the L-type $\mathrm{Ca} 2+$ channel alpha1 subunit and reduced ischemia/reperfusion injury. Circ. Res., 2006, 98, 403-411.

[85] Nunez, L.; Vaquero, M.; Gomez, R.; Caballero, R.; MateosCaceres, P.; Macaya, C.; Iriepa, I.; Galvez, E.; Lopez-Farre, A.; Tamargo, J.; Delpon, E. Nitric oxide blocks hKv1.5 channels by Snitrosylation and by a cyclic GMP-dependent mechanism. Cardiovasc. Res., 2006, 72, 80-89.

[86] Ahmmed, G.U.; Xu, Y.; Hong Dong, P.; Zhang, Z.; Eiserich, J.; Chiamvimonvat, N. Nitric oxide modulates cardiac $\mathrm{Na}(+)$ channel via protein kinase A and protein kinase G. Circ. Res., 2001, 89, 1005-1013.

[87] William, M.; Hamilton, E.J.; Garcia, A.; Bundgaard, H.; Chia K.K.; Figtree, G.A.; Rasmussen, H.H. Natriuretic peptides stimulate the cardiac sodium pump via NPR-C-coupled NOS activation. Am. J. Physiol .Cell. Physiol., 2008, 294, C1067-C1073.

[88] Xu, K.Y.; Kuppusamy, S.P.; Wang, J.Q.; Li, H.; Cui, H.; Dawson, T.M.; Huang, P.L.; Burnett, A.L.; Kuppusamy, P.; Becker, L.C. Nitric oxide protects cardiac sarcolemmal membrane enzyme function and ion active transport against ischemia-induced inactivation. $J$. Biol. Chem., 2003, 278, 41798-41803.

[89] Tamargo, J.; Caballero, R.; Gomez, R.; Delpon, E. Cardiac electrophysiological effects of nitric oxide. Cardiovasc. Res., 2010, 87, 593-600.

[90] Danik, S.B.; Rosner, G.; Lader, J.; Gutstein, D.E.; Fishman, G.I.; Morley, G.E. Electrical remodeling contributes to complex tachyarrhythmias in connexin43-deficient mouse hearts. FASEB J, 2008, 22, 1204-1212.

[91] Gutstein, D.E.; Morley, G.E.; Tamaddon, H.; Vaidya, D.; Schneider, M.D.; Chen, J.; Chien, K.R.; Stuhlmann, H.; Fishman, G.I. Conduction slowing and sudden arrhythmic death in mice with cardiac-restricted inactivation of connexin43. Circ. Res., 2001, 88, 333-339.

[92] Danik, S.B.; Liu, F.; Zhang, J.; Suk, H.J.; Morley, G.E.; Fishman, G.I.; Gutstein, D.E. Modulation of cardiac gap junction expression and arrhythmic susceptibility. Circ. Res., 2004, 95, 1035-1041.

[93] Gonczi, M.; Papp, R.; Kovacs, M.; Seprenyi, G.; Vegh, A. Modulation of gap junctions by nitric oxide contributes to the antiarrhythmic effect of sodium nitroprusside? Br. J. Pharmacol., 2009, 156, 786-793.

[94] Jackson, P.E.; Feng, Q.P.; Jones, D.L. Nitric oxide depresses connexin 43 after myocardial infarction in mice. Acta. Physiol. (Oxf)., 2008, 194, 23-33.

[95] Hoffmann, A.; Gloe, T.; Pohl, U.; Zahler, S. Nitric oxide enhances de novo formation of endothelial gap junctions. Cardiovasc. Res., 2003, 60, 421-430.

[96] Rodenas, J.; Mitjavila, M.T.; Carbonell, T. Nitric oxide inhibits superoxide production by inflammatory polymorphonuclear leukocytes. Am. J. Physiol., 1998, 274, C827-C830.

[97] Clancy, R.M.; Leszczynska-Piziak, J.; Abramson, S.B. Nitric oxide, an endothelial cell relaxation factor, inhibits neutrophil superoxide anion production via a direct action on the NADPH oxidase. J. Clin. Invest., 1992, 90, 1116-1121.

[98] Sohn, H.Y.; Krotz, F.; Gloe, T.; Keller, M.; Theisen, K.; Klauss, V.; Pohl, U. Differential regulation of xanthine and NAD(P)H oxidase by hypoxia in human umbilical vein endothelial cells. Role of nitric oxide and adenosine. Cardiovasc. Res., 2003, 58, 638-646.

[99] Pleskova, M.; Beck, K.F.; Behrens, M.H.; Huwiler, A.; Fichtlscherer, B.; Wingerter, O.; Brandes, R.P.; Mulsch, A.; Pfeilschifter, J. Nitric oxide down-regulates the expression of the catalytic NADPH oxidase subunit Nox1 in rat renal mesangial cells. FASEB. J., 2006, 20, 139-141

[100] Harrison, C.B.; Drummond, G.R.; Sobey, C.G.; Selemidis, S. Evidence that nitric oxide inhibits vascular inflammation and superoxide production via a 447 phox-dependent mechanism in mice. Clin. Exp. Pharmacol. Physiol., 2010, 37, 429-434. 
[101] Rodrigo, R.; Vinay, J.; Castillo, R.; Cereceda, M.; Asenjo, R.; Zamorano, J.; Araya, J.; Castillo-Koch, R.; Espinoza, J.; Larrain, E. Use of vitamins $\mathrm{C}$ and $\mathrm{E}$ as a prophylactic therapy to prevent postoperative atrial fibrillation. Int. J. Cardiol., 2010, 138, 221-228.

[102] Liu, T.; Li, G. Antioxidant interventions as novel preventive strategies for postoperative atrial fibrillation. Int J Cardiol, 2009, 145(1), $140-142$.

[103] Kiss, A.; Juhasz, L.; Seprenyi, G.; Kupai, K.; Kaszaki, J.; Vegh, A. The role of nitric oxide, superoxide and peroxynitrite in the antiarrhythmic effects of preconditioning and peroxynitrite infusion in anaesthetized dogs. Br. J. Pharmacol., 2010, 160, 1263-1272.

[104] Liao, Z.; Yin, D.; Wang, W.; Zeng, G.; Liu, D.; Chen, H.; Huang, Q.; He, M. Cardioprotective effect of sasanquasaponin preconditioning via bradykinin-NO pathway in isolated rat heart. Phytother. Res., 2009, 23, 1146-1153.

[105] Abramson, J.L.; Hooper, W.C.; Jones, D.P.; Ashfaq, S.; Rhodes, S.D.; Weintraub, W.S.; Harrison, D.G.; Quyyumi, A.A.; Vaccarino, V. Association between novel oxidative stress markers and Creactive protein among adults without clinical coronary heart disease. Atherosclerosis., 2005, 178, 115-121.

[106] Burger, D.; Lei, M.; Geoghegan-Morphet, N.; Lu, X.; Xenocostas, A.; Feng, Q. Erythropoietin protects cardiomyocytes from apoptosis via up-regulation of endothelial nitric oxide synthase. Cardiovasc. Res., 2006, 72, 51-59.

[107] Schulz, R.; Kelm, M.; Heusch, G. Nitric oxide in myocardial ischemia/reperfusion injury. Cardiovasc. Res., 2004, 61, 402-413.

[108] Feuerstein, G.Z. Apoptosis in cardiac diseases--new opportunities for novel therapeutics for heart diseases. Cardiovasc. Drugs. Ther., 1999, 13, 289-294.

[109] Lin, Y.K.; Lu, Y.Y.; Chen, Y.C.; Chen, Y.J.; Chen, S.A. Nitroprusside modulates pulmonary vein arrhythmogenic activity. J. Biomed. Sci., 2010, 17, 20 .

[110] Whalen, E.J.; Johnson, A.K.; Lewis, S.J. Effects of nitric oxide synthase inhibition on sympathetically-mediated tachycardia. Eur. J. Pharmacol., 1999, 365, 217-223.

[111] Toda, N.; Okamura, T. Modulation of renal blood flow and vascular tone by neuronal nitric oxide synthase-derived nitric oxide. $J$. Vasc. Res., 2010, 48, 1-10.

[112] Rossi, N.F.; Maliszewska-Scislo, M.; Chen, H.; Black, S.M.; Sharma, S.; Ravikov, R.; Augustyniak, R.A. Neuronal nitric oxide synthase within paraventricular nucleus: blood pressure and baroreflex in two-kidney, one-clip hypertensive rats. Exp. Physiol., 2010, 95, 845-857.

[113] Young, C.N.; Fisher, J.P.; Gallagher, K.M.; Whaley-Connell, A.; Chaudhary, K.; Victor, R.G.; Thomas, G.D.; Fadel, P.J. Inhibition of nitric oxide synthase evokes central sympatho-excitation in healthy humans. J. Physiol., 2009, 587, 4977-4986.

[114] Haissaguerre, M.; Jais, P.; Shah, D.C.; Takahashi, A.; Hocini, M.; Quiniou, G.; Garrigue, S.; Le Mouroux, A.; Le Metayer, P.; Clementy, J. Spontaneous initiation of atrial fibrillation by ectopic beats originating in the pulmonary veins. N. Engl. J. Med., 1998, 339, 659-666.

[115] Haissaguerre, M.; Jais, P.; Shah, D.C.; Garrigue, S.; Takahashi, A.; Lavergne, T.; Hocini, M.; Peng, J.T.; Roudaut, R.; Clementy, J. Electrophysiological end point for catheter ablation of atrial fibril- lation initiated from multiple pulmonary venous foci. Circulation, 2000, 101, 1409-1417.

[116] Hu, Y.F.; Chen, Y.C.; Cheng, C.C.; Higa, S.; Chen, Y.J.; Chen, S.A. Fluvastatin reduces pulmonary vein spontaneous activity through nitric oxide pathway. J. Cardiovasc. Electrophysiol., 2009, 20, 200-206.

[117] Han, W.; Li, W.M.; Song, L.Y.; Li, Y.; Yang, S.S.; Huang, Y.L.; Gan, R.T.; Kou, J.J.; Geng, J.Q. The experimental study on changes of endothelial nitric oxide synthase and plasminogen activator inhibitor-1 protein in the canine atrial fibrillation model. Zhonghua Xin Xue Guan Bing Za Zhi., 2005, 33, 69-72.

[118] Cai, H.; Li, Z.; Goette, A.; Mera, F.; Honeycutt, C.; Feterik, K.; Wilcox, J.N.; Dudley, S.C., Jr.; Harrison, D.G.; Langberg, J.J. Downregulation of endocardial nitric oxide synthase expression and nitric oxide production in atrial fibrillation: potential mechanisms for atrial thrombosis and stroke. Circulation, 2002, 106, 2854-2858

[119] Ziegler, T.; Silacci, P.; Harrison, V.J.; Hayoz, D. Nitric oxide synthase expression in endothelial cells exposed to mechanical forces. Hypertension., 1998, 32, 351-5.

[120] Rizzo, V.; McIntosh, D.P.; Oh, P.; Schnitzer, J.E. In situ flow activates endothelial nitric oxide synthase in luminal caveolae of endothelium with rapid caveolin dissociation and calmodulin association. J. Biol. Chem., 1998, 273, 34724-34729.

[121] Corson, M.A.; James, N.L.; Latta, S.E.; Nerem, R.M.; Berk, B.C.; Harrison, D.G. Phosphorylation of endothelial nitric oxide synthase in response to fluid shear stress. Circ. Res., 1996, 79, 984-991.

[122] Li, L.; Rezvan, A.; Salerno, J.C.; Husain, A.; Kwon, K.; Jo, H.; Harrison, D.G.; Chen, W. GTP cyclohydrolase I phosphorylation and interaction with GTP cyclohydrolase feedback regulatory protein provide novel regulation of endothelial tetrahydrobiopterin and nitric oxide. Circ. Res., 2010, 106, 328-336.

[123] Widder, J.D.; Chen, W.; Li, L.; Dikalov, S.; Thony, B.; Hatakeyama, K.; Harrison, D.G. Regulation of tetrahydrobiopterin biosynthesis by shear stress. Circ. Res., 2007, 101, 830-838.

[124] Guazzi, M.; Arena, R. Endothelial dysfunction and pathophysiological correlates in atrial fibrillation. Heart., 2009, 95, 102-106.

[125] Balenovic, D.; Bencic, M.L.; Udovicic, M.; Simonji, K.; Hanzevacki, J.S.; Barisic, I.; Kranjcevic, S.; Prkacin, I.; Coric, V.; Brcic, L.; Coric, M.; Brcic, I.; Borovic, S.; Radic, B.; Drmic, D.; Vrcic, H.; Seiwerth, S.; Sikiric, P. Inhibition of methyldigoxininduced arrhythmias by pentadecapeptide BPC 157: a relation with NO-system. Regul. Pept., 2009, 156, 83-89.

[126] Imani, A.; Faghihi, M.; Sadr, S.S.; Niaraki, S.S.; Alizadeh, A.M. Noradrenaline protects In vivo rat heart against infarction and ventricular arrhythmias via nitric oxide and reactive oxygen species. $J$. Surg. Res., 2011, $169(1), 9-15$.

[127] Imaizumi, S.; Miura, S.; Nakamura, K.; Kiya, Y.; Uehara, Y.; Zhang, B.; Matsuo, Y.; Urata, H.; Ideishi, M.; Rye, K.A.; Sata, M.; Saku, K. Antiarrhythmogenic effect of reconstituted high-density lipoprotein against ischemia/reperfusion in rats. J. Am. Coll. Cardiol., 2008, 51, 1604-1612.

[128] Shen, J.; Wang, J.; Zhao, B.; Hou, J.; Gao, T.; Xin, W. Effects of EGb 761 on nitric oxide and oxygen free radicals, myocardial damage and arrhythmia in ischemia-reperfusion injury in vivo. Biochim. Biophys. Acta., 1998, 1406, 228-236. 